\title{
Learning Word Meanings from Teachers' Repeated Story Read-Aloud in EFL Primary Classrooms
}

\author{
Lu-Chun $\operatorname{Lin}^{1}$ \\ ${ }^{1}$ Institute of Teaching English to Speaskers of Other Langauges, National Chiao Tung University, Taiwan \\ Correspondence: Lu-Chun Lin, Language Teaching and Research Center, National Chiao Tung University, 1001 \\ University Road, Hsinchu City 30010, Taiwan. E-mail: reginelin@g2.nctu.edu.tw
}

Received: April 21, 2014 Accepted: May 27, 2014 Online Published: June 13, 2014

doi:10.5539/elt.v7n7p68 URL: http://dx.doi.org/10.5539/elt.v7n7p68

\begin{abstract}
This study used a quasi-experimental design to determine the effects of teachers' story read-aloud on EFL elementary school students' word learning outcomes. It specifically examined whether the word learning was enhanced by teachers' repeated story read-aloud and word-meaning explanations and further determined whether the learning outcomes were related to children's English proficiency. Two native English-speaking teachers read a story to their fourth-grade classes four times. The results showed that increasing frequency of story read-aloud yielded greater word-learning gains across time. The EFL children, on average, learned approximately half of the target words by the third read-aloud. While both high- and low-proficiency groups showed significant vocabulary gains with the frequency of teachers' read-aloud, the high-proficiency children consistently outperformed their low-proficiency peers, especially on the L1 meaning-matching vocabulary test. The overall findings were quite encouraging and showed empirical evidence that teachers' repeated story read-aloud can be an effective way to facilitate elementary school children's word learning in a context where English is a foreign language.
\end{abstract}

Keywords: EFL, elementary school, story read-aloud, vocabulary learning, repetition, English proficiency

\section{Introduction}

Listening to stories is a common and enjoyable activity inside and outside a language classroom (Holdaway, 1982; Wells, 1986). Stories provide linguistic, paralinguistic, discourse, and cultural information for children to develop their language skills in a meaningful context. It also provides children with opportunities to develop decontextualized language skills and has been suggested to contribute to vocabulary growth and language development (Elley, 1989; Heath, 1983; Krashenand, 1989; Robbins \& Ehri, 1994). Teachers reading stories to students in a foreign language in the elementary school is also considered to benefit language learners who often have relatively limited exposure to a rich spoken environment in the target foreign language (Kirsch, 2012). However, teachers teaching English as a foreign language (EFL) in Asian countries often find themselves confined to set curricula and prescribed English textbooks which contain mostly premodified simple dialogues or texts written at students' proficiency level. Given the limited class time available and rigid curriculum to follow (Sheu, 2006), teachers may not be compelled or convinced to devote class time to reading storybooks to their students. A corpus-based study (Hsieh, Wang, \& Lee, 2011) specifically examined and compared the language input in the EFL elementary textbooks with 65 storybooks used in a storytelling programme (Wang \& Lee, 2007). It was found that the storybooks provide richer language input than the textbooks in terms of more diverse vocabulary, sentence patterns, and culture information within more authentic and meaningful contexts. The researchers thus suggested that reading storybooks aloud to young EFL learners can help to promote a variety of English skills related to oral and literacy development and should be integrated into the EFL elementary school curriculum.

This study explored the use of story read-aloud as a context for learning word meanings in EFL classrooms. It specifically examined whether the word learning was enhanced by teachers' repeated story read-aloud and word-meaning explanations and further determined whether the learning outcomes were related to children's English proficiency. 


\subsection{Listening to Stories and Vocabulary Learning}

One most noticeable benefit of listening to stories is the potential for learning new words. Substantial research has shown that children of different age groups learn new words from listening to stories, such as children in preschool (Karweit \& Wasik, 1996; Sénéchal, Thomas, \& Monker, 1995; Wasik \& Bond, 2001), in kindergarten (Eller, Pappas, \& Brown, 1988; Robbins \& Ehri, 1994), and in primary grades (Brabham \& Lynch-Brown, 2002; Brett, Rothlein, \& Hurley, 1996; Elley, 1989; Nicholson \& Whyte, 1992; Penno, Wilkinson, \& Moore 2002; Wilkinson \& Houston-Price, 2012). One of the earliest studies on vocabulary learning from listening to stories was conducted by Elley (1989) who provided empirical evidence of vocabulary learning from listening to stories read aloud by classroom teachers. The seven- and eight-year-old native-speaking children in New Zealand obtained vocabulary gains of $15 \%$ after listening to a story read aloud three times in one week without teachers' explanation of the target words. The results of the delayed posttest further found that these vocabulary gains were still evident three months later and the decline in the mean scores was almost negligible. Similar findings of word learning from listening to stories were later supported by Robbins and Ehri (1994) who found that story listening contributed modestly to the vocabulary gains of 38 preliterate kindergarten children after listening to stories twice.

Only few published studies examined how teachers' story read-aloud might affect students' vocabulary learning in a primary foreign language classroom (Kirsch, 2012). A recent study by Kirsch (2012) anlaysed a German teacher's teaching strategies during the storytelling events in a modern foreign language classroom in England and examined how Year 6 children learned new German words from the teacher's storytelling. The findings showed that this experienced German-speaking teachers employed a range of teaching strategies (e.g., mime, gesture, voice modulation, paraphrase) and provided multiple and meaningful interactions with and among students for language use. During the storytelling events, both explicit and incidental learning was observed, and the students were found engaging in activities which allowed them to focus on the meaning, form, and usage of the new words. The analysis of the lesson observation, the interviews, and post-test further suggested that the children were able to recall considerable number of words and sentences over a period of time. The study identified a number of factors associated with the positive impact of the teacher's storytelling on vocabulary learning, such as a repetitive story text, the frequency of encounters, the children's sustained engagement and participation, and effective teaching strategies that allowed for both explicit and incidental learning etc. This study, however, is a classroom-based study involving only six focal children. The design of the study could not elucidate whether the focal children's vocabulary gains were a direct result of the teacher's storytelling. A more systematic investigation with more sensitive measures may more precisely assess the effects of teachers' story read-aloud on vocabulary learning among elementary school students and offer a clearer picture of different factors associated with vocabulary learning outcomes in a foreign language classroom.

\subsection{Frequency of Story Read-Aloud}

Previous studies have identified several variables that are associated with the story comprehension or word-learning outcomes from teachers' read-aloud, and the frequency of story read-aloud is one of the important factors. For example, Robbins and Ehri (1994) suggested that when the target words were not emphasized during story read-aloud, kindergarten children were more likely to learn and remember target words in their native language (L1) when stories were read four times than only twice. Biemiller and Boote (2006) further considered several variables (i.e., pre-testing effects, number of read-aloud sessions, and word-meaning explanations) that have been shown to contribute to vocabulary learning during read-aloud sessions. They concluded that primary-grade students in Canada, of whom 50\% were English-language learners (ELLs), learned more word meanings from multiple exposures to a story read aloud combined with teacher explanations of new words.

These findings were further confirmed by a recent study by Wilkinson and Houston-Price (2012) who examined whether 7- and 9-year-old English-speaking children's learning of difficult words was facilitated by presenting words in a variety of story contexts, rather than repeatedly in the same story context. One-half of the children heard three stories which contained the same target vocabulary on three occasions, while the other half heard the same story repeatedly for three times. The researchers hypothesized that encountering words in multiple contexts (i.e., different stories) would 'allow the child to create a larger network of semantic associations between the new word and related concepts and hence to embed the word more successfully within the lexicon' (Wilkinson \& Houston-Price, 2012, p. 16). However, the results showed that hearing words in a variety of story contexts did not lead to more gains in word knowledge than hearing words within the same story repeated for three times. In fact, there was some evidence that younger children's word learning may have been negatively affected by hearing words presented in different story contexts. The study therefore concluded that it is the repeated exposure of words in context, rather than words presented in varying contexts, that is necessary for children to 
develop understanding of new vocabulary.

In sum, research to date has shown that multiple encounters of new words in repeated readings of the same story are beneficial for children to develop understanding of new vocabulary (Beck, McKeown, \& Kucan, 2002) and are essential for learning different levels of word knowledge about the form-meaning link (Schmitt, 2010).

\subsection{Entering Vocabulary Knowledge and Language Proficiency}

Children's entering vocabulary knowledge or language proficiency is another important factor that might influence their word-learning outcomes. Several studies, such as Collins (2010), Justice et al. (2005), Penno et al. (2002), Reese and Cox (1999), Robbins and Ehri (1994), and Sénéchal et al. (1995), have suggested that children with higher initial vocabulary knowledge made greater word-learning gains when teachers read a story aloud than did children with lower initial vocabulary knowledge. For example, in Penno et al.'s study (2002), while all four ability groups made pretest-posttest vocabulary gains, higher-ability L1 children scored significantly more target words and generalization words on the multiple-choice tests than did the lower-ability children. In the story-retelling task, children of higher ability again showed more accurate usage of the target words than did children of lower ability. Similarly, an efficacy study with at-risk kindergartners, Justice et al. (2002) included children with clinically depressed vocabulary knowledge. The results showed that there was no differential effect between pretest and posttest for children with low vocabulary knowledge under the condition of mere repeated story listening. The same group of children, however, made significant gains under the condition of repeated story listening with elaborated word exposure (e.g., word meaning explanation). The researchers highlighted the importance of the elaboration of novel words or adult mediation when children with lower ability encounter unfamiliar words while listening to stories.

Consistent with previous studies with L1 children, a recent study by Collins (2010) involving ELLs in the U.S. also demonstrated a robust effect of initial English vocabulary knowledge on target word acquisition. Apparently, repeated exposure to story read-aloud sessions did not appear to overcome the "Matthew Effect", as the higher-ability children still made greater vocabulary gains from story read-aloud interventions than did the lower ability children across all conditions (Penno et al., 2002; Sénéchal et al., 1995; Wilkinson \& Houston-Price, 2012). The researcher suggested that ELL children with higher initial English vocabulary may have more well-developed working repertoire, higher motivation to learn new words, and better working memory. Collins' claim echoes Sénéchal et al.'s (1995) hypothesis that more skilled language learners have more efficient word retrieval processes which could result in greater word gains from exposure to novel words in a story read-aloud context.

\subsection{Research Questions}

While much has been researched about a variety of factors and their roles in children's ability to learn new words from listening to stories (Penno, Wilkinson, \& Moore, 2002), these studies were mostly carried out with native-English-speaking children or ELLs within an English-dominant context (Collins, 2010). In addition, the majority of these studies used commercially available storybooks and acknowledged the limitation of not being able to control for confounding factors such as out-of-class exposure to the stories and target words. There is a need to systematically investigate whether and how children in foreign language classrooms learn new words from teachers' story read-aloud. Thus, this study used the quasi-experimental design to empirically examine the effects of frequency of teachers' read-aloud with word meaning explanations and students' English proficiency on students' word learning outcomes. On the basis of the extant literature, the following two research questions were addressed:

1) To what extent does frequency of teachers' story read-aloud influence Taiwanese EFL children's learning of novel words?

2) To what extent are the children's English proficiency levels related to their word learning outcomes within a repeated read-aloud context?

\section{Method}

\subsection{Participants}

A total of 58 children from two fourth-grade classes in two urban public elementary schools in northern Taiwan participated in this study. All were native speakers of Mandarin Chinese and were learning English as a foreign language. Thirteen children were later excluded from the data analyses due to absences during the pre-test or any of the subsequent four read-aloud sessions, resulting in a final sample of 45 students. The children began formal English education in Grade 1, but their out-of-school English learning experiences differed widely, ranging from 0 to 6 years of experience. At the time of data collection, all of the participants had received at least three-year 
formal English instruction in their schools, where three 40-minute English class sessions were offered each week in the fourth grade. The city where the two elementary schools located has been implementing an EFL team-teaching programme which recruits native English-speaking teachers to teach English with local English teachers to elementary school students in all grades since 2001 (Luo, 2006). Two sessions were taught by local licensed teachers with a specialization in English education; the other was taught by native-speaking English teachers with a college degree and teaching certificate from their home countries. Although the children in this study had received three years of formal English teaching, most of their English proficiency was still at the beginning level according to the Movers' level of the Cambridge Young Learners English Test (YLE).

\subsection{Stimuli: A Wordless Picture Book and Novel Words}

Instead of using a commercially available storybook, the researcher created a storybook (see Appendix A) to ensure that the participants did not have prior or concurrent exposure to the stimulus book. The use of a wordless picture book prevented participants from reading instead of listening to the story during the read-aloud sessions. The story was illustrated in color and depicts two aliens; one is rejected by others because of his ugly body features, and the other is popular because of his special talent. The popular alien, presented as a bully, likes to tease his unpopular classmate, but the rejected alien does not give up and works hard at turning disadvantages into advantages. Later in a school sports competition, the rejected alien helps his popular classmate and the team to turn the tables in a near-defeated game. The once-rejected protagonist becomes the hero, and the popular alien learns to appreciate others on a deeper level.

Eight pseudo words (Table 1) were embedded in the story as target words to assure a true zero knowledge of the target words for all participants. The pseudo words represent fictional objects, such as the alien species, the aliens' special body features and particular body motions, and adjectives associated with the body features; hence, the application of these words is restricted to this particular storybook. The target pseudo words comprised three word classes with four nouns, two verbs, and two adjectives ${ }^{1}$. All nouns and verbs were one syllable long, while the two adjectives were two syllables long to represent a typical adjective ending $-y$. The frequencies of occurrence of the target words in each word class were carefully considered. Half of the nouns appeared four times, and the other nine times. One verb and one adjective occurred four times, while another verb and adjective occurred only twice. Later word analysis showed that the frequencies of occurrence of the target vocabulary within the story were not significantly correlated with the target vocabulary scores across the three sessions $(p$ $=.79, .43$, and .06 respectively). A repeated measure two-way ANOVA with word frequency (i.e., two, four, and nine occurrences) as the between-group factor also did not show significant differences among three frequency groups, $F(2,5)=0.52, p=.62$, partial $\eta^{2}=0.17$.

Table 1. The eight target words

\begin{tabular}{lll}
\hline Target Words & Parts of Speech & Example Sentences from the story \\
\hline fap & noun & A little fap named Willy is different from everybody else. \\
spok & noun & All faps like to play a game called spok. \\
tas & noun & When his classmates see Willy's tas, they all stop and stare at him. \\
vit & noun & Chucky has a vit on his back. \\
smig & verb & The tas would smig the sopk and miss the goal. \\
woop & verb & He can woop his vit and hit the spok into the goal. \\
drinny & adjective & What an ugly and drinny thing you have on your head! \\
flisty & adjective & It's shinny and flisty. \\
\hline
\end{tabular}

\subsection{Tests}

The children's English proficiency was measured by the Movers' level of the Cambridge YLE test. The test has been commonly used to assess the English proficiency of EFL or ESL elementary school children (Alptekin, Ercetin, \& Bayyurt, 2007; Atay \& Kurt, 2006; Butler \& Lee, 2006, 2010). The listening and reading-writing subtests were administered in the pre-test, and a median split of the raw scores was used to divide the children into high- and low-proficiency groups. The level of Movers shows a child is beginning to deal with everyday written and spoken English at a very basic level and has a vocabulary of 700 words (LTTC, 2013). 
Two types of meaning recognition tests in a multiple-choice format, one for picture identification and the other for L1 meaning-matching, were designed to measure the children's vocabulary learning from teachers' read-aloud sessions. While the picture identification test is a common form of vocabulary tests for L1 and L2 children, the multiple-choice L1 translation test is suggested as a valid and less cognitively challenging vocabulary test for L2 learners (Nation, 2001). To ensure that the participants' vocabulary learning were not a result of learning from the repetitive testing, an additional eight low-frequency words which did not appear in the story and were unlikely to be known by the EFL children were included to serve as the control words. For both tests, the target or control word was orally presented by the teachers and was not presented in written form on the answer booklet. The participants needed to select one correct picture or one correct Chinese synonym word out of three options. Across three testing sessions, the order of all vocabulary questions and their three-choice items were randomized to minimize the practice effects.

\subsection{Design and Procedures}

The present study adopted a quasi-experimental design to examine the effects of repeated story listening on children's vocabulary growth. The quasi-experimental design was used because the use of self-developed stimuli story and pseudowords allowed us to examine the effect of the target variables and exercise control over extraneous variables (e.g., prior and external exposure to the target words); thus, a control group and a target vocabulary pretest were not necessary.

Data collection lasted approximately five weeks. The YLE proficiency test was administered before the story read-aloud sessions. For each class, the native English-speaking teacher guided by scripted procedures read the stimulus story to the whole class four times, each session separated by approximately one week. The scripted story-reading protocol and possible responses to children's questions during each reading were provided to the teachers and were strictly followed to ensure procedural fidelity across the sessions and across the two EFL classes. In both classes, the children sat on their own, and the pictures of the story were shown to them in PowerPoint slides while the teachers were reading aloud. Before reading aloud the story, the teachers told the children that a good listener listened carefully and quietly. Conversation initiated by the children was kept to a minimum by acknowledging their comments and gently asking them to refocus, steering them back to the story so as not to distract from the activity. Procedural fidelity was monitored by a graduate research assistant who conducted an on-site fidelity check and video recorded all the read-aloud sessions. Confirmation was obtained from both teachers and across all sessions that the protocol had been followed.

To provide an explanation for each target word, this study followed the guidelines used for word explanation by Elley (1989) and Penno et al. (2002). When encountering the target word for the first time during the read-aloud session, the teachers explained the word by (a) first pointing to a picture in the book, (b) then providing a synonymous phrase or definitional information about the word, and (c) finally acting out the word wherever applicable. Each time a target word was repeated in the story, a simpler preface with an abbreviated definition or explanation was provided.

To determine the effect of the frequency of teachers' read-aloud, the vocabulary post-tests were administered at the end of the first, third, and fourth sessions. The decision regarding which sessions to provide the vocabulary post-tests was seemingly arbitrary but was actually influenced by previous research. Previous empirical studies have shown that one-time story reading only generated limited word learning gains in L1 children (see review by Swanborn \& de Glopper, 1999); therefore, at least three presentations of a story have been proposed for improved word learning (Brett et al., 1996; Collins, 2010; Penno et al., 2002). It was therefore assumed that EFL children may need to hear a story at least three times to learn the novel words in the story. Given the potential pedagogical implication, this study decided to assess the participants' knowledge of target words in certain sessions to present a possible linear effect of repeated story listening over time. To reduce a fatigue effect to some extent, vocabulary testing in the second session was then deliberately skipped. Each session, including story read-aloud and vocabulary assessment, lasted about 30 minutes except for the second session in which vocabulary assessment was not given.

\section{Results and Discussion}

Table 2 presents the descriptive statistics of the variables in the study. English proficiency scores represented the sum of raw scores on the listening and reading-writing subtests, and the target word scores comprised the sum of scores from the picture identification and L1 meaning-matching tests. Multiple-choice vocabulary tests comprised both the target words and the low-frequency control words, and their mean scores across three sessions were presented in Figure 1. To preclude the possibility that the participants' word-learning gains were a result of the repeated testing, a one-way repeated measures ANOVA with the number of read-aloud sessions as 
the within-subject factor was first conducted for the eight low-frequency control words. No significant difference across the three sessions was found, $F(2,88)=0.17, p=.84$, partial $\eta^{2}=.004$. In addition, across the three testing sessions, there was a large main effect of word type, $F(1,44)=34.36, p<.001$, partial $\eta^{2}=0.44$, revealing that scores for the target words were significantly higher than scores for the control words obtained by chance level. Therefore, this study concluded that the participants' learning of the target words, if any, was attributable to exposure to teachers' read-aloud and word-meaning explanations instead of the repeated testing.

Table 2. Descriptive statistics for the English proficiency scores and vocabulary raw scores at the three read-aloud sessions $(n=45)$

\begin{tabular}{llll}
\hline Test scores (maximum scores) & $M$ & $S D$ & Range \\
\hline English proficiency (45) & 22.2 & 10.3 & $8-45$ \\
Listening (20) & 10.9 & 4.8 & $2-20$ \\
Reading-Writing (25) & 11.2 & 6.5 & $2-25$ \\
\hline Target words at 1st read-aloud (16) & 5.4 & 3.3 & $0-16$ \\
Picture identification (8) & 2.5 & 1.8 & $0-8$ \\
L1 meaning-matching (8) & 2.9 & 2.1 & $0-8$ \\
Control words (16) & 4.7 & 2.8 & $0-11$ \\
\hline Target words at 3 ${ }^{\text {rd }}$ read-aloud (16) & 7.3 & 3.6 & $0-16$ \\
Picture identification (8) & 3.8 & 2.2 & $0-8$ \\
L1 meaning-matching (8) & 3.5 & 1.9 & $0-8$ \\
Control words (16) & 4.7 & 2.5 & $0-11$ \\
\hline Target words at 4 ${ }^{\text {th }}$ read-aloud (16) & 7.0 & 4.4 & $0-15$ \\
Picture identification (8) & 3.4 & 2.3 & $0-8$ \\
L1 meaning-matching (8) & 3.5 & 2.4 & $0-8$ \\
Control words (16) & 4.5 & 2.7 & $0-10$ \\
\hline
\end{tabular}

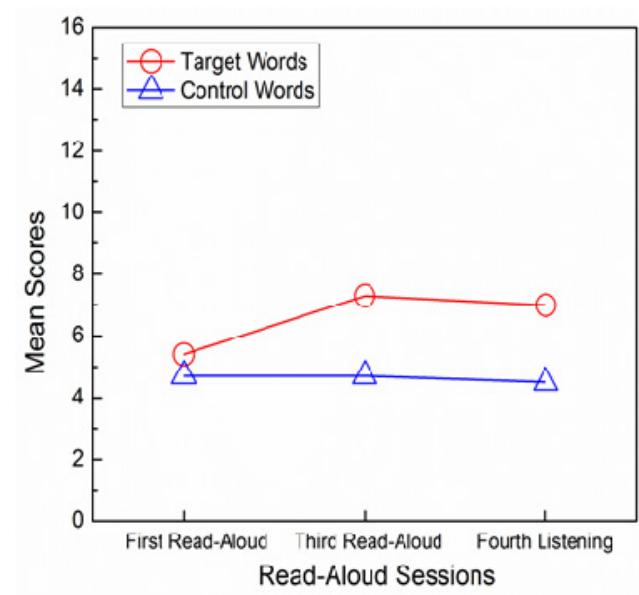

Figure 1. Mean scores for the target words and low-frequency control words across the three sessions

The overall mean number of the target words correctly identified by the children in the fourth session was 7.0, suggesting that the EFL children in this study learned almost half of the target words meanings by the fourth listening. This word learning outcome is similar to the result reported by Elley (1989) in a study with English-speaking children in New Zealand who listened to two stories three times. Two story read-aloud conditions were compared, one story read-aloud with teachers' explanation of target words and one without explanation. The teachers in the explanation condition provided word explanations in a way similar to that in the 
present study; target words were explained to the children by teachers providing a synonym, acting out the words, or pointing to the illustration depicting the words. The children in the explanation condition obtained $40 \%$ of word gains as compared to $15 \%$ of gains in the no-explanation condition. Similar findings concerning word learning from listening to stories was also demonstrated by Wilkinson and Houston-Price (2012) with 7- and 9 -year-olds in England. They found that both younger and older children learned some knowledge of around half of the words they encountered in stories. The results of the present study were quite encouraging and demonstrated that teachers' story read-aloud can be an effective way to facilitate elementary school children's word learning in a context where English is a foreign language.

\subsection{Effects of Frequency of Teachers' Read-Aloud}

The effect of the number of read-aloud sessions on the children's word learning was analysed using the repeated measure ANOVA with significant results being further analysed by post-hoc Bonferroni corrected $t$ tests for multiple comparisons. A significant main effect of the number of sessions was found, $F(2,88)=7.48, p=.002$, partial $\eta^{2}=.15$. Subsequent post-hoc Bonferroni $t$ tests showed that the children's knowledge of the target words significantly improved during the third and fourth read-aloud session as compared to the first one, but there was no significant difference between the third and fourth sessions. To estimate the magnitude of the effects of the number of read-aloud sessions, Cohen's $d$ was calculated to report the effect sizes, for which an effect size of 0.20-0.50 was considered small, 0.50-0.80 modest, and 0.80 large. Table 3 shows the results of the post-hoc multiple-comparison tests and the effect-size estimates for the differences in vocabulary scores for the three sessions. Positive and modest effect sizes were also found for the differences in vocabulary scores between the first versus the third and the first versus the fourth read-aloud sessions.

Table 3. Results of the post-hoc Bonferroni adjustment and effect-size estimates for the vocabulary score differences between the sessions

\begin{tabular}{lll}
\hline Number of read-aloud session & Significance & Effect size \\
\hline $1^{\text {st }}$ vs. $3^{\text {rd }}$ session & $.00^{*}$ & 0.55 \\
$1^{\text {st }}$ vs. $4^{\text {th }}$ session & $.047^{*}$ & 0.41 \\
$3^{\text {rd }}$ vs. $4^{\text {th }}$ session & 1.00 & 0.07 \\
\hline
\end{tabular}

Note. ${ }^{*} p<.05$

The findings indicate that EFL children did learn novel words from teachers' repeated story read-aloud and word-meaning explanations, and increasing the frequency of teachers' read-aloud yielded greater word-learning gains over time. The fourth session, however, did not further contribute to EFL children's word learning in comparison to the third, suggesting that while repeated read-aloud led to significant word-learning gains, such progress seemed to stagnate at the fourth session. Biemiller and Boote (2006) in their study with L1 children also found that first and second-grade children learned nearly similar numbers of words when the storybooks were read twice compared to four times. Although the underlying causes are relatively vague regarding whether early-grade children need to listen to stories two or more times, the researchers suggested that more word meanings can be taught if the same book is read aloud more than twice because different word meanings are usually conveyed at different times of reading. Similarly, a more recent study by Wilkinson and Houston-Price (2012) examined whether word learning was facilitated by hearing the target words in three different stories rather than hearing the words in the same story repeated for three times and found that no significant benefit for presenting words in a variety of story contexts. In fact, there was some suggestion of a negative effect of context variety on younger children's word learning. The researchers therefore concluded that children's word learning is best facilitated by exposures to the words in repeated context.

Taking a separate look at the two vocabulary subtests, i.e., picture identification and L1 meaning-matching tests, the overall mean scores of the two tests for the whole group of $45 \mathrm{EFL}$ fourth graders trended similarly to the analysis of the total target vocabulary scores, but the effect of the frequency of teachers' read-aloud was only significant for the picture identification test, $F(2,88)=9.44, p<.001$, partial $\eta^{2}=.17$. The children correctly identified more target words on the picture identification test in the third and fourth sessions than they did in the first session (Table 4). There was, however, no significant difference between the third and fourth sessions. Increasing the frequency of reading aloud to students, on the other hand, did not significantly improve the students' performance on the L1 meaning-matching test. 
Table 4. Results of the post-hoc Bonferroni adjustment and effect-size estimates for the differences in picture identification test scores between the sessions

\begin{tabular}{lll}
\hline Number of read-aloud session & Significance & Effect size \\
\hline $1^{\text {st }}$ vs. $3^{\text {rd }}$ read-aloud session & $.01^{*}$ & 0.65 \\
$1^{\text {st }}$ vs. $4^{\text {th }}$ read-aloud session & $.04^{*}$ & 0.44 \\
$3^{\text {rd }}$ vs. $4^{\text {th }}$ read-aloud session & .36 & 0.18 \\
\hline
\end{tabular}

Note. ${ }^{*} p<.05$

The L1 meaning-matching test was apparently less straightforward than the picture identification test. It is likely that EFL children need to establish a certain level of English proficiency before they can effectively draw on their L1 vocabulary knowledge to successfully learn novel English words. In addition, the two teachers in this study were native speakers of English and knew very little Chinese. They were asked to faithfully follow the scripted story-reading protocol, which did not provide Chinese translation or explanations for the target words. The majority of participants, however, was beginning EFL learners and may not have yet had the L2 ability to disentangle the context clues in the story and to successfully map new L2 words to L1 translations. According to the Revised Hierarchical Model proposed by Kroll and Stewart (1994), in early stages of L2 word learning, new L2 words are understood or learned mostly through lexical-level translation connections to first language words rather than through underlying concepts. The access to L1 translation words affects the way L2 words are being learned; and the conceptual or semantic processing involved changed gradually as L2 proficiency increases. Thus, the present findings point to the potential importance of providing an L1 translation of the target words in the read-aloud sessions for EFL children with limited English proficiency.

A practical conclusion arising from the present findings is that repeated reading aloud to young EFL learners is beneficial for their vocabulary learning. However, most EFL teachers and students are inclined to the belief that reading is the major source of vocabulary acquisition in an instructed L2 or foreign language context (Laufer 2003). Others may not be convinced of the role that repeated exposure plays in word learning and, as a result, do not see the value of devoting class time to multiple readings of the same story. For example, Tang and Nesi (2003) compared the lexical environment of EFL secondary-school classrooms in Hong Kong to those in Guangzhou. Both teachers were frequently observed engaging in the explicit teaching of preselected words in textbook readings. However, most of the unplanned words, which incidentally occurred during instruction, received relatively fewer vocabulary-teaching treatments and were taught only once. The researchers noted that teachers and students in both locations believed in the explicit teaching and learning of words and emphasized the repeated productions of the words mainly in oral drills. Such vocabulary teaching practice is also commonly observed in the EFL classrooms in Taiwan, where new words receive thorough and systematic treatments but are generally found to be quite impoverished in the lexical environment. Thus, this study suggests that incorporating repeated read-aloud and teacher explanations of new words into the EFL curriculum not only allows teachers to provide richer and more meaningful lexical input but also provides English learners the opportunity to learn words incrementally.

\subsection{Effects of the Children's English Proficiency}

In examining the effect of participants' individual differences on their ability to learn words from listening to stories, the present study used EFL children's general English proficiency as the between-subject factor instead of children's initial vocabulary knowledge considered in previous studies. For one, the EFL children in this study had limited English vocabulary which might weaken the possible effect of the individual differences. For another, there is not yet a reliable EFL vocabulary test available to the best of our knowledge. General English proficiency, measured by a standardized test such as YLE, is considered a better indicator of the resources that beginning EFL children use to learn words through teachers' story read-aloud.

A median split, based on the English proficiency scores, was used to divide the children into high $(n=21, M=$ $30.8, S D=8.4)$ and low proficiency $(n=24, M=14.6, S D=3.5)$ groups. Figure 2 shows the target vocabulary mean scores of the high- and low-proficiency groups across three sessions. Vocabulary scores increased with the frequency of teachers' read-aloud for both groups, with the high-proficiency group performing consistently better than the low-proficiency group. Both groups showed a marked increase during the third read-aloud session. There was a slight but non-significant decrease at the fourth session for the low-proficiency group. Table 5 further compares the mean scores on the target vocabulary test of the high- and low-proficiency groups. 
Independent $t$-tests yielded significant between-group differences with medium to large effect sizes across three sessions.

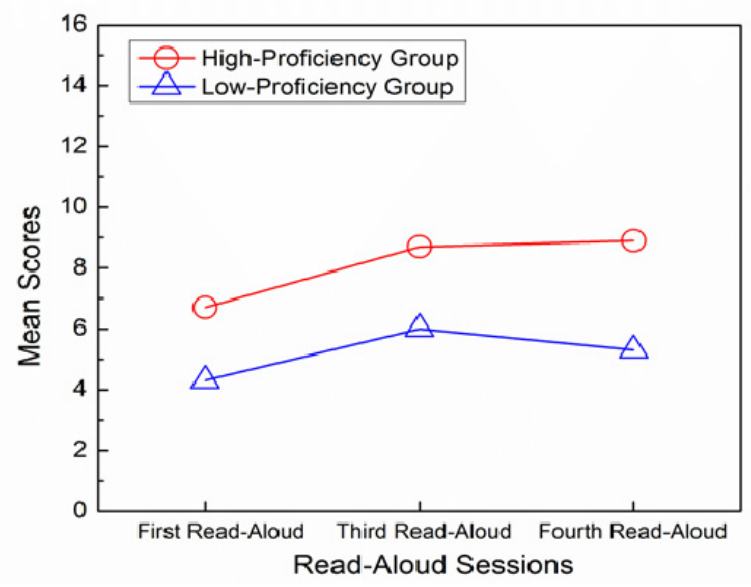

Figure 2. Mean scores on the target vocabulary tests across the three sessions for the high- and low-proficiency groups

Table 5. Comparisons between high- and low-proficiency groups' mean scores on the YLE test and its subtests, target vocabulary test and subtests across the three sessions

\begin{tabular}{|c|c|c|c|c|c|c|c|}
\hline & \multicolumn{2}{|c|}{$\operatorname{High}(n=21)$} & \multicolumn{2}{|c|}{ Low $(n=24)$} & \multirow{2}{*}{$t$} & \multirow{2}{*}{$p$} & \multirow{2}{*}{$d$} \\
\hline & $M$ & $S D$ & $M$ & $S D$ & & & \\
\hline English proficiency (45) & 30.8 & 8.4 & 14.6 & 3.5 & 8.2 & $0.00^{*}$ & 2.52 \\
\hline Listening (20) & 14.7 & 3.5 & 7.7 & 2.9 & 7.2 & $0.00^{*}$ & 2.18 \\
\hline Reading-Writing (25) & 16.1 & 5.7 & 6.9 & 3.1 & 6.6 & $0.00 *$ & 2.01 \\
\hline $1^{\text {st }}$ read-aloud (16) & 6.7 & 3.8 & 4.3 & 2.3 & 2.49 & $0.02 *$ & 0.76 \\
\hline Picture id. (8) & 3.1 & 2.0 & 2.0 & 1.6 & 2.02 & 0.05 & 0.61 \\
\hline L1 meaning $(8)$ & 3.7 & 2.4 & 2.3 & 1.6 & 2.39 & $0.02 *$ & 0.69 \\
\hline $3^{\text {rd }}$ read-aloud (16) & 8.7 & 4.3 & 6.0 & 2.2 & 2.58 & $0.02 *$ & 0.79 \\
\hline Picture id. (8) & 4.3 & 2.5 & 3.3 & 1.8 & 1.45 & 0.16 & 0.55 \\
\hline L1 meaning $(8)$ & 4.5 & 2.0 & 2.7 & 1.3 & 3.41 & $0.00 *$ & 1.07 \\
\hline $4^{\text {th }}$ read-aloud (16) & 8.9 & 4.4 & 5.3 & 3.6 & 3.01 & $0.01 *$ & 0.90 \\
\hline Picture id. (8) & 4.4 & 2.2 & 2.5 & 2.0 & 3.13 & $0.00^{*}$ & 0.90 \\
\hline L1 meaning (8) & 4.4 & 2.6 & 2.8 & 1.9 & 2.47 & $0.02 *$ & 0.70 \\
\hline
\end{tabular}

Note. Picture id. $=$ picture identification test; L1 meaning= L1 meaning-matching test.

$* p<.05$

When further comparing the between-group differences in the two vocabulary subtests, the results showed that the high-proficiency children consistently performed better on the L1 meaning-matching test than their low-proficiency peers did, corroborating the previous assumption that EFL children with higher English proficiency had a stronger ability to associate novel English words with their L1 translations. Although the effect of English proficiency either did not reach or only approached marginal significance $(p=0.05$ and 0.16 respectively) for the picture identification test in the first and third session, the effect sizes of 0.61 and 0.55 indicated that the mean difference between the two groups is modest relative to the variance and that the differences might be of some importance. By the fourth session, however, the high-proficiency children scored significantly higher than the less-proficient children, who showed a significant drop in scores on the fourth picture identification test from the third test (paired-sample $t(23)=-3.31, p=.00, d=-0.46$ ). 
These results confirmed those of previous investigations in that language learners' initial language abilities have a significant effect on their word-learning outcomes, with the higher-ability children achieving higher scores on the vocabulary tests (Collins, 2010; Justice, Meier, \& Walpole, 2005; Penno et al., 2002). The differences appeared even more pronounced over time. In Collins' study (2010) with L2 children in the U.S., the discrepancy in word-learning gains of the two ability groups was attributed to variations in the children's experiences with stories, their skills in using contextual cues to detect meanings for unfamiliar words, their motivation to learn new words, and their working memory. In particular, the ability to use contextual cues has been found to be crucial for inferring word meanings and learning new words (Harley \& Hart 2000). This is especially true when learners must be able to effectively use contextual cues and integrate known information derived from the words they already know with the new information needed to determine the meanings of unfamiliar words. EFL learners with limited English proficiency often have difficulties when applying their available cognitive, metacognitive, and compensatory resources in L1 to learning English (Lan \& Oxford, 2003), and their insufficient English vocabulary prevents them from engaging in successful lexical inferences. This also explains the relatively low scores on the L1 meaning-matching test among the low-proficiency children in the present study. In other words, knowledge of a second language influences the ability to draw on L1 or other cognitive resources and affects the rate of efficiency of processing higher-level cues, such as the semantic, syntactic, and contextual cues available when teachers read aloud (Coyne, McCoach, \& Kapp, 2007). Such a causal relation is apparently bidirectional (Robbins \& Ehri, 1994). Our findings regarding the beginning EFL learners further add to the example of the Matthew effect in vocabulary learning, suggesting that L2 learners with better L2 proficiency and larger L2 vocabulary have a comparative advantage over less-proficient learners in learning more words when stories are read aloud.

\section{Conclusion and Implications}

The present study provided empirical evidence showing that story read-aloud can be a valuable classroom activity for EFL children who often have relatively limited exposure to rich spoken English. One main finding is that multiple exposures combined with teachers' explanations of novel words did help EFL children's vocabulary learning and might be crucial for less-able language learners. However, repeated exposure alone did not close the achievement gap between the high and low-proficiency groups. Given the less satisfactory word-learning gains for the low-proficiency children, this study corroborated previous research studies (Sonbul \& Schmitt, 2010) suggesting that an ideal vocabulary instruction for EFL children should incorporate both the direct teaching of words (Laufer, 2003) and vocabulary learning through multiple opportunities to encounter novel words in authentic and interesting texts (Maynard, Pullen, \& Coyne, 2010). Less-able children, in particular, are not likely to learn new words from just listening to stories. Literacy interventions studies have shown that at-risk children's word learning is enhanced when a story read-aloud session incorporates both explicit vocabulary instruction and follow-up curricular activities that engaged children in using the book-related words (Wasik, Bond, \& Hindman, 2006); and these findings may also be applicable to the beginning EFL learners.

Despite the positive results obtained in this study, there are several limitations that future research could address. The most notable limitation is that this study like other quasi-experimental studies had to carefully consider or stringently control particular variables and may not bear a resemblance to the typical story read-aloud situation in an EFL classroom. For example, the wordless picture book used and the eight pseudo words targeted in this study were specifically developed for the experimental purpose; the teachers were asked to faithfully implement the story read-aloud protocol and to keep the interaction or further discussion initiated by the children to a minimum. Despite of such a controlled story-delivery condition, the children in this study still learned almost half of the target word meanings. If the teachers had been allowed to provide more discussion or activities about the target words or the story, even a greater amount of learning might have occurred.

A second limitation is the use of the multiple-choice format in the vocabulary measurement which gauged the participants' vocabulary knowledge over time precludes us from generalizing the results to overall vocabulary learning. The multiple-choice format only assessed whether the children was broadly familiar with the meaning of each target words, but it is limited in its ability to reveal the depth of children's word knowledge (Wilkinson \& Houston-Price, 2012). Further, word learning involves an array of skills including the recognition of a word's speech sounds and orthographic composition or spelling, the awareness of its grammatical, lexical, and semantic properties, and the ability to use it in context (Cook, 2008). Future research administering improved vocabulary measures that tap other aspects of target vocabulary knowledge or productive use of the newly learned words will provide a more complete picture of learning words from listening to stories.

Owing to the nature of classroom research, it is acknowledged that the findings are based on a small number of participants and should be interpreted with caution. However, the medium effect size observed clearly confirms 
the benefit of repeated story listening for incidental vocabulary learning. Future studies with more classrooms and with EFL children at different age or proficiency levels are required to support and extend the current findings.

Finally, the major findings of this study are only peripherally concerned with two factors considered to be essential for vocabulary learning within the context of story read-aloud in EFL elementary school classrooms. Previous studies have also identified other important variables that affect the vocabulary learning outcomes including different instructions of target vocabulary (Maynard et al., 2010), the frequency and saliency of the target words (Ellis, 2002; Vermeer, 2001), the types of contextual clues for lexical inferencing (Ellis, 1994; Nassaji, 2003; Zahar, Cobb, \& Spada, 2001), types of read-aloud texts (Bortnem, 2008; Brabham, Boyd, \& Edgington, 2000; Elliott \& Dupuis, 2002), and teachers' read-aloud styles (Brabham \& Lynch-Brown, 2002; Teale \& Martinez, 1996). This study is the first attempt to empirically explore and relate two major factors influencing EFL children's word learning from teachers' story read-aloud. The next step in this line of research is to further investigate additional variables such as types of vocabulary instructions, teachers' read-aloud styles, and read-aloud texts. We hope the findings of this line of research will encourage teachers in EFL programmes to develop and integrate effective vocabulary instruction into their classroom story read-aloud. Future research is warranted to identify specific instructional practices which can facilitate and possibly accelerate word learning for beginning foreign-language learners.

\section{Acknowledgments}

This study was supported by a research grant from Taiwan National Science Council (NSC 99-2410-H-009-065). I wish to thank the two participating teachers and their students for their patience and commitment throughout the experiment.

\section{References}

Alptekin, C., Ercetin, G., \& Bayyurt, Y. (2007). The effectiveness of a theme-based syllabus for young L2 learners. Journal of Multilingual and Multicultural Development, 28, 1-17. http://dx.doi.org/10.2167/jmmd470.1

Atay, D., \& Kurt, G. (2006). Elementary school EFL learners' vocabulary learning: The effects of post-reading activities. Canadian Modern Language Review, 63, 255-273. http://dx.doi.org/10.3138/cmlr.63.2.255

Beck, I. L., McKeown, M. G., \& Kucan, L. (2002). Bringing words to life: Robust vocabulary instruction. New York: Guilford Press.

Biemiller, A., \& Boote, C. (2006). An effective method for building meaning vocabulary in primary grades. Journal of Educational Psychology, 98, 44-62. http://dx.doi.org/10.1037/0022-0663.98.1.44

Bortnem, G. M. (2008). Teacher use of interactive read alouds using nonfiction in early childhood classrooms. Journal of College Teaching and Learning, 5, 29-44. Retrieved from http://journals.cluteonline.com/index.php/TLC/article/viewArticle/1213

Brabham, E. G., Boyd, P., \& Edgington, W. D. (2000). Sorting it out: Elementary students' responses to fact and fiction in informational storybooks as read-alouds for science and social studies. Literacy Research and Instruction, 39, 265-289. http://dx.doi.org/10.1080/19388070009558326

Brabham, E. G., \& Lynch-Brown, C. (2002). Effects of teachers' reading-aloud styles on vocabulary acquisition and comprehension of students in the early elementary grades. Journal of Educational Psychology, 94, 465-473. http://dx.doi.org/10.1037/0022-0663.94.3.465

Brett, A., Rothlein, L., \& Hurley, M. (1996). Vocabulary acquisition from listening to stories and explanations of target words. The Elementary School Journal, 96, 415-422. http://dx.doi.org/10.1086/461836

Butler, Y. G., \& Lee, J. (2006). On-task versus off-task self-assessments among Korean elementary school students studying English. The Modern Language Journal, 90, 506-518.

Butler, Y. G., \& Lee, J. (2010). The effects of self-assessment among young learners of English. Language Testing, 27, 5-31. http://dx.doi.org/10.1111/j.1540-4781.2006.00463.x

Collins, M. F. (2010). ELL preschoolers' English vocabulary acquisition from storybook reading. Early Childhood Research Quarterly, 25, 84-97. http://dx.doi.org/10.1016/j.ecresq.2009.07.009

Cook, V. (2008). Second language learning and language teaching (4th ed.). New York: Oxford University Press.

Coyne, M. D., McCoach, D. B., \& Kapp, S. (2007). Vocabulary intervention for kindergarten students: 
Comparing extended instruction to embedded instruction and incidental exposure. Learning Disability Quarterly, 30, 74-88. http://dx.doi.org/10.2307/30035543

Eller, R. G., Pappas, C. C., \& Brown, E. (1988). The lexical development of kindergartners: Learning from written context. Journal of Reading Behaviour, 20, 5-24. http://dx.doi.org/10.1080/10862968809547621

Elley, W. B. (1989). Vocabulary acquisition from listening to stories. Reading Research Quarterly, 24, 174-187. http://dx.doi.org/10.1086/461836

Elliott, J. B., \& Dupuis, M. M. (2002). Young adult literature in the classroom: Reading it, teaching it, loving it. Newark, DE: International Reading Association.

Ellis, N. C. (2002). Frequency effects in language processing: A review with implications for theories of implicit and explicit language acquisition. Studies in Second Language Acquisition, 24, 143-188. http://dx.doi.org/10.1017/S0272263102002024

Ellis, R. (1994). Factors in the incidental acquisition of second language vocabulary from oral input: A review essay. Applied Language Learning, 5, 1-32.

Harley, B., \& Hart, D. (2000). Vocabulary learning in the content-oriented second-language classroom: Student $\begin{array}{llll}\text { perceptions and } & \text { Language Awareness, } & \text { 9(2), }\end{array}$ http://dx.doi.org/10.1080/09658410008667139

Heath, S. B. (1983). Ways with words: Language, life, and work in communities and classrooms. Cambridge, NY: Cambridge University Press.

Holdaway, D. (1982). Shared book experience: Teaching reading using favorite books. Theory into Practice, 21, 293-300. http://dx.doi.org/10.1080/00405848209543021

Hsieh, M. Y., Wang, F. Y., \& Lee, S. Y. (2011). English acquisition through storytelling: A corpus-based analysis of and comparison between school texts and storybooks. International Journal of Foreign Language Teaching, 1(6), 25-33.

Justice, L. M., Meier, J., \& Walpole, S. (2005). Learning new words from storybooks: An efficacy study with at-risk kindergartners. Language, Speech, and Hearing Services in Schools, 36, 17-32. http://dx.doi.org/10.1044/0161-1461

Karweit, N., \& Wasik, B. A. (1996). The effects of story reading programmes on literacy and language development of disadvantaged preschoolers. Journal of Education for Students Placed at Risk, 1, 319-348. http://dx.doi.org/10.1207/s15327671espr0104_4

Kirsch, C. (2012). Using storytelling to teach vocabulary in language lessons: Does it work? The Language Learning Journal, 1-19. http://dx.doi.org/10.1080/09571736.2012.733404

Krashen, S. (1989). We acquire vocabulary and spelling by reading: Additional evidence for the input hypothesis. Modern Language Journal, 73, 440-464.

Kroll, J. F., \& Stewart, E. (1994). Category interference in translation and picture naming: Evidence for asymmetric connections between bilingual memory representations. Journal of Memory and Language, 33, 149-149. http://dx.doi.org/10.1006/jmla.1994.1008

Lan, R., \& Oxford, R. L. (2003). Language learning strategy profiles of elementary school students in Taiwan. International Review of Applied Linguistics in Language Teaching, 41, 339-379. http://dx.doi.org/10.1515/iral.2003.016

Laufer, B. (2003). Vocabulary acquisition in a second language: Do learners really acquire most vocabulary by reading? Some empirical evidence. Canadian Modern Language Review, 59, 567-587. http://dx.doi.org/10.3138/cmlr.59.4.567

Luo, W.-H. (2006). Collaboration between native and non-native English-speaking teachers: How does it work? The Journal of Asia TEFL, 3, 41-58. Retrieved from http://www.earticle.net/Article.aspx?sn=182115

Maynard, K. L., Pullen, P. C., \& Coyne, M. D. (2010). Teaching vocabulary to first-grade students through repeated shared storybook reading: A comparison of rich and basic instruction to incidental exposure. Literacy Research and Instruction, 49, 209-242. http://dx.doi.org/10.1080/19388070902943245

Nassaji, H. (2003). L2 vocabulary learning from context: Strategies, knowledge sources, and their relationship with success in L2 lexical inferencing. Tesol Quarterly, 37, 645-670. http://dx.doi.org/10.2307/3588216

Nation, I. S. P. (2001). Learning vocabulary in another language. New York: Cambridge University Press. 
Nicholson, T., \& Whyte, B. (1992). Matthew effects in learning new words while listening to stories. In C. K. D. Leu (Ed.), Literacy research, theory, and practice: Views from many perspectives (pp. 499-503). Chicago, IL: National Reading Conference.

Penno, J. F., Wilkinson, I. A. G., \& Moore, D. W. (2002). Vocabulary acquisition from teacher explanation and repeated listening to stories: Do they overcome the Matthew effect? Journal of Educational Psychology, 94, 23-33. http://dx.doi.org/10.1037/0022-0663.94.1.23

Reese, E., \& Cox, A. (1999). Quality of adult book reading affects children's emergent literacy. Developmental Psychology, 35, 20-28. http://dx.doi.org/10.1037/0012-1649.35.1.20

Robbins, C., \& Ehri, L. C. (1994). Reading storybooks to kindergartners helps them learn new vocabulary words. Journal of Educational Psychology, 86, 54-64. http://dx.doi.org/10.1037/0022-0663.86.1.54

Schmitt, N. (2010). Researching vocabulary: A vocabulary research manual. New York, NY: Palgrave Macmillan.

Sénéchal, M., Thomas, E., \& Monker, J. A. (1995). Individual differences in 4-year-old children's acquisition of vocabulary during storybook reading. Journal of Educational Psychology, 87, 218-229. http://dx.doi.org/10.1037/0022-0663.87.2.218

Sheu, H.-C. (2006). The challenges of using English picture story books with primary school students in Taiwan. English Teaching and Learning, 30, 39-60. Retrieved from http://www.airitilibrary.com/Publication/alDetailedMesh?docid=10237267-200604-30-4s-39-60-a

Sonbul, S., \& Schmitt, N. (2010). Direct teaching of vocabulary after reading: Is it worth the effort? ELT Journal, 64, 253-260. http://dx.doi.org/10.1093/elt/ccp059

Swanborn, M. S. L., \& de Glopper, K. (1999). Incidental word learning while reading: A meta-analysis. Review of Educational Research, 69, 261-285. http://dx.doi.org/10.3102/00346543069003261

Tang, E., \& Nesi, H. (2003). Teaching vocabulary in two Chinese classrooms: Schoolchildren's exposure to English words in Hong Kong and Guangzhou. Language Teaching Research, 7, 65-97. http://dx.doi.org/10.1191/13621688031r113oa

Teale, W. H., \& Martinez, M. G. (1996). Reading aloud to young children: Teachers' reading styles and kindergartners' text comprehension. In C. Pontecorvo (Ed.), Children's early text construction (pp. 321-344). Mahwah, N.J.: Erlbaum.

The Language Training and Testing Centre. (2013). YLE-general description. Retrieved from http://www.lttc.ntu.edu.tw/YLE_General_Description.htm

Vermeer, A. (2001). Breadth and depth of vocabulary in relation to L1/L2 acquisition and frequency of input. Applied Psycholinguistics, 22, 217-234. http://dx.doi.org/10.1017/S0142716401002041

Wang, F. Y., \& Lee, S. Y. (2007). Storytelling is the bridge. The International Journal of Foreign Language Teaching, 3, 30-35. Retrieved from http://www-o.ntust.edu.tw/ syying.lee/publications/ Story_telling_is_the_bridge_IJETL.pdf

Wasik, B. A., \& Bond, M. A. (2001). Beyond the pages of a book: Interactive book reading and language development in preschool classrooms. Journal of Educational Psychology, 93, 243-250. http://dx.doi.org/10.1037/0022-0663.93.2.243

Wasik, B. A., Bond, M. A., \& Hindman, A. (2006). The effects of a language and literacy intervention on head start children and teachers. Journal of Educational Psychology, 98, 63-74. http://dx.doi.org/10.1037/0022-0663.98.1.63

Wells, C. G. (1986). The meaning makers: Children learning language and using language to learn. Portsmouth, N.H.: Heinemann.

Wilkinson, K. S., \& Houston-Price, C. (2012). Once upon a time, there was a pulchritudinous princess...: The role of word definitions and multiple story contexts in children's learning of difficult vocabulary. Applied Psycholinguistics, 1-23. http://dx.doi.org/10.1017/S0142716411000889

Zahar, R., Cobb, T., \& Spada, N. (2001). Acquiring vocabulary through reading: Effects of frequency and contextual richness. Canadian Modern Language Review, 57, 541-572. http://dx.doi.org/10.3138/cmlr.57.4.541 


\section{Note}

Note 1. The three word classes were analysed by two-way repeated measure ANOVA with the frequency of teachers' read-aloud as the within-subject factor and word classes as the between-subject factor. Although the between-group difference in the word learning outcomes did not reach statistical significance at the .05 level, the effect size was 0.43 , which is by convention considered moderate $F(2,5)=1.91, p=.24$, partial $\eta^{2}=.43$. On average, the EFL children in this study learned more novel nouns $(M=38.5)$ than novel adjectives $(M=31.3)$ and verbs $(M=24.5)$ across the three sessions. It is possible that too few instances (i.e., two and four) for each word class led to low statistical power and limited comparisons of learnability of different word classes. The analysis of the learnability of different word classes is beyond the scope of the present study, but is certainly a worthy topic for future research.

\section{Appendix}

The Story of Willy and Chucky

Thousands of miles from the Earth, on the far far side of the universe, is a small planet. On the planet live a group of aliens called faps.

A little fap named Willy is different from everybody else, because he has a tas on his head and nobody else does. The tas is ugly and drinny. And it doesn't look pretty.

One of Willy's classmates named Chucky has a vit on his back. It's shinny and flisty. Everybody thinks the vit is very cool, and they like Chucky very much. So Chucky is very proud of himself, but he is not nice at all.

Willy goes to school like everyone. When his classmates see Willy's tas, they all stop and stare at him. Chucky points at him and laughs, "What an ugly and drinny thing you have on your head!" Willy feels very very sad.

In the P.E. class, all faps like to play a game called spok. And Chucky is very good at this game. He can woop his vit and hit the spok into the goal. As long as Chucky plays the game, his team always wins.

Willy also wants to play spok with his classmates. But his tas always gets him in trouble. When he tries to hit the spok with his head, the tas would smig the spok and miss the goal. Chucky laughs at him, "What an ugly and drinny thing you have on your head!" So nobody wants Willy to be in the team.

Every day after school, Willy practises playing the game by himself. He tries to smig the spok with his tas again and again, but he never smigs it into the goal. He says to himself, "I know I can do it!" So every day he keeps on practicing.

One day Willy's class competes with the other class. The faps in the other class are very good at this game. Chucky plays very hard with his classmates but they are going to lose the game.

Suddenly, somebody passes the spok to Chucky. Chucky tries to woop it with his vit. He falls down and hurts his vit. It doesn't look shinny and flisty anymore. The class thinks they are going to lose the game, and everyone looks very very sad. Then Willy thinks he should do something to help the team. He says to the class, "Let me play for Chucky."

Nobody thinks Willy would score. Willy still plays to his best. He gets his tas ready, and as the spok flies near him, he smigs it very hard. And boom, the spok flies straight into 100-point goal, which nobody in the class has done so before. Not even Chucky.

Everyone cheers for Willy and they lift him up on their shoulders. "Hooray!" they all shout. "Hooray for Willy's tas!" And nobody thinks Willy's tas is ugly and drinny anymore.

From then on, everybody likes Willy just like they like Chucky. The end.

\section{Copyrights}

Copyright for this article is retained by the author(s), with first publication rights granted to the journal.

This is an open-access article distributed under the terms and conditions of the Creative Commons Attribution license (http://creativecommons.org/licenses/by/3.0/). 